\title{
Thermal and Optical Properties of Dibenzothiophene-Based Poly(tetramethylsilarylenesiloxane) Derivatives
}

\author{
Ruri Okura $^{1}$, Ryuzi Katoh ${ }^{2}$, Tsukasa Ichikawa ${ }^{2 *}$, and Nobukatsu Nemoto ${ }^{2 *}$ \\ 1 Graduate School of Engineering, Nihon University, Koriyama, Fukushima, Japan \\ 2 College of Engineering, Nihon University, Koriyama, Fukushima, Japan \\ * Corresponding authors: E-mail: nemoto.nobukatsu@nihon-u.ac.jp; \\ ichikawa.tsukasa@nihon-u.ac.jp
}

\begin{abstract}
The synthesis of dibenzothiophene derivative, i.e., 2,8-bis(trimethylsilyl)dibenzothiophene (3a) and dibenzothiophene-based poly(tetramethylsilarylenesiloxane) derivative (P1) was attained. In addition, 2,8-bis(trimethylsilyl)dibenzothiophene-5,5'-dioxide (3aO) and oxidized dibenzothiophene-based poly(tetramethylsilarylenesiloxane) derivative (P10) were obtained by oxidation reaction of $\mathbf{3} \mathbf{a}$ and $\mathbf{P} \mathbf{1}$, respectively. The glass transition temperature was raised by the oxidation of the dibenzothiophene-based poly(tetramethylsilarylenesiloxane) derivative. The introduction of alkylsilyl groups onto dibenzothiophene derivatives induced no remarkable red shifts in the absorption as well as fluorescence spectra; however, the red shifts in the fluorescence spectra were observed by oxidation of dibenzothiophene derivatives.

Key words: dibenzothiophene, poly(tetramethylsilarylenesiloxane), fluorescence, thermal properties
\end{abstract}

\section{INTRODUCTION}

Dibenzothiophene is a $\pi$-conjugated molecule and a typical sulfur-containing compound in light oil.[1] Therefore, dibenzothiophene has been expected to be applied in the field of organic electronics for optical utilization; however, few studies on the utilization of dibenzothiophene derivatives have been reported. ${ }^{[2-4]}$ In addition, deviation of electric charge is generated when sulfonyl moieties as electron-withdrawing groups are derived by oxidizing the sulfur moiety at 5-position of dibenzothiophene to result in the optical properties different from those of derivatives bearing dibenzothiophene moiety. ${ }^{[5]}$

On the other hand, the red-shifts of the wavelength in the absorption as well as emission spectra and the improvement of the fluorescence quantum yields have been reported by introducing alkylsilyl groups onto the aromatic ring. ${ }^{[6-9]}$ Our research group has also reported that poly(tetramethylsilarylenesiloxane) derivatives where the aromatic moiety is introduced into the main chain component of polysiloxane improve the heat resistance and fluorescence quantum yield. ${ }^{[10-15]}$

Based on the above background, we synthesized dibenzothiophene derivatives with trimethylsilyl groups as well as poly(tetramethylsilarylenesiloxane) derivatives bearing dibenzothiophene moiety as shown in Scheme 1 in this research. In addition, oxidized compounds of the above-mentioned derivatives were also prepared. We will present the thermal and optical properties of the resulting derivatives and discuss the characteristic fluorescence properties of new dibenzothiophene derivatives with alkylsilyl groups.

\section{EXPERIMENTAL}

\subsection{Materials}

Dibenzothiophene, $m$-chloroperbenzoic acid ( $m$-CPBA), chlorotrimethylsilane, chlorodimethylsilane, (Tokyo Chemical Industry Co., Ltd), bromine, $2.76 \mathrm{~mol} / \mathrm{L} n$ - butyllithium $(n-\mathrm{BuLi})$ in hexane, $31 \%$ hydrogen peroxide, acetic acid, dichloromethane, (KANTO CHEMICAL CO., INC), and $5 \%$ palladium on charcoal (Sigma-Aldrich Co. LLC) were used as received. Tetrahydrofuran (THF) and benzene (KANTO CHEMICAL CO., INC) were used after distillation over sodium. Chloroform (KANTO CHEMICAL CO., INC) was used after distillation over calcium hydride. 2,8-Dibromodibenzothiophene was prepared by the method reported earlier. ${ }^{[4]} 1,1,3,3$ Tetramethylguanidinium 2-ethylhexanoate was obtained from the equimolar mixture of 1,1,3,3-tetramethylguanidine and 2-ethylhexanoic acid (Tokyo Chemical Industry Co., Ltd). ${ }^{[10-15]}$

\subsection{Measurements}

${ }^{1} \mathrm{H}$ and ${ }^{13} \mathrm{C}$ NMR spectra were recorded on a JEOL ECX400 spectrometer in deuterated dimethyl sulfoxide (DMSO$d_{6}$ ) or chloroform $\left(\mathrm{CDCl}_{3}\right)$ at ambient temperature. FT-IR spectra were measured on a Perkin-Elmer Spectrum One FT-IR spectrometer. Glass transition temperature $\left(T_{\mathrm{g}}\right)$ and melting temperature $\left(T_{\mathrm{m}}\right)$ were determined by differential scanning calorimetry (DSC) on a RIGAKU ThermoPlus DSC $8230 \mathrm{~L}$ at a heating rate of $10{ }^{\circ} \mathrm{C} / \mathrm{min}$ under a nitrogen flow rate of $10 \mathrm{~mL} / \mathrm{min}$. Thermogravimetry analysis (TGA) was performed on a RIGAKU ThermoPlus TG8110 at a heating rate of $10^{\circ} \mathrm{C} /$ min under a nitrogen atmosphere. Number-average $\left(M_{\mathrm{n}}\right)$ and weight-average $\left(M_{\mathrm{w}}\right)$ molecular weights were estimated by size-exclusion chromatography (SEC) on a SHOWA DENKO Shodex GPC-101 system with polystyrene gel columns (a pair of Shodex GPC LF-804), eluted with THF using a calibration curve of polystyrene standards. Emission spectra were measured on a Shimadzu RF-5300PC spectrophotometer. Fluorescence quantum yield $\left(\Phi_{\mathrm{F}}\right)$ was determined in $\mathrm{CHCl}_{3}$ using a HAMAMATSU PHOTONICS absolute PL quantum yield measured system C11347. The optimized geometrical structures and the energies for the highest occupied 
molecular orbital (HOMO) and the lowest unoccupied molecular orbital (LUMO) were estimated by the density functional theory (DFT) calculations at B3LYP/6-31G(d) level of theory using Spartan '08 for Windows (Wavefunction, Inc., Irvine, CA, USA).

\subsection{Synthesis}

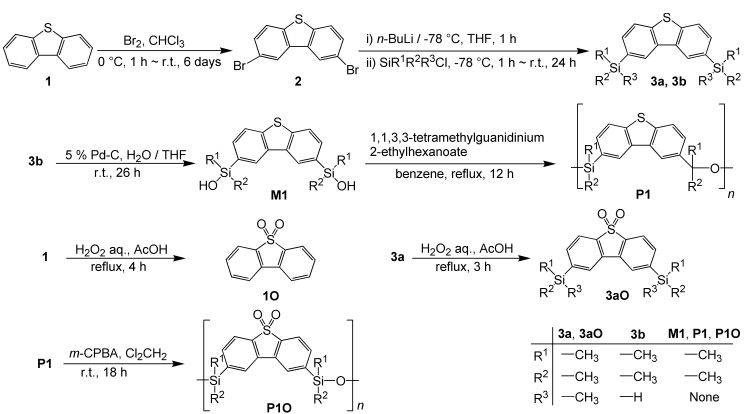

Scheme 1. Synthesis of dibenzothiophene derivatives

\subsubsection{2,8-Bis(trimethylsilyl)dibenzothiophene (3a)}

Under a dry argon atmosphere, $2.76 \mathrm{~mol} / \mathrm{L} n$-BuLi (3.4 $\mathrm{mL}, 9.38 \mathrm{mmol}$ ) was added dropwise to 2,8dibromodibenzothiophene $(2,1.20 \mathrm{~g}, 3.51 \mathrm{mmol})$ dissolved in dry THF $(40 \mathrm{~mL})$ at $-78^{\circ} \mathrm{C}$ and the reaction mixture was stirred for $1 \mathrm{~h}$. Then, chlorotrimethylsilane (1.55 g 14.3 mmol) was added dropwise to this solution. After the reaction mixture was stirred for $24 \mathrm{~h}$ at ambient temperature, it was poured into $30 \mathrm{~mL}$ of water. The crude product was extracted with ethyl acetate and the organic layer was washed with water and sodium chloride aqueous solution, successively, dried over anhydrous magnesium sulfate, and filtered. After the filtrate was concentrated under reduced pressure, the product was purified by silica gel column chromatography using hexane as eluent. The collected fraction with an $R_{\mathrm{f}}$ value of 0.53 was concentrated under reduced pressure to afford 2,8-bis(trimethylsilyl)dibenzothiophene as colorless liquid with the yield of $92 \%$ (1.06 g, $3.23 \mathrm{mmol}$ ).

${ }^{1} \mathrm{H}-\mathrm{NMR}\left(\mathrm{CDCl}_{3}, 400 \mathrm{MHz}\right): \delta 0.37\left[\mathrm{~s}, 18 \mathrm{H},-\mathrm{Si}\left(\mathrm{CH}_{3}\right)_{3}\right]$, 7.58-7.61 $(\mathrm{m}, 2 \mathrm{H}$, aromatic protons), 7.84-7.86 (m, $2 \mathrm{H}$, aromatic protons), 8.32 (s, $2 \mathrm{H}$, aromatic protons). ${ }^{13} \mathrm{C}$ $\mathrm{NMR}\left(\mathrm{CDCl}_{3}, 100 \mathrm{MHz}\right): \delta 122.2$ (aromatic carbon), 126.2 (aromatic carbon), 131.4 (aromatic carbon), 134.8 (aromatic carbon), 135.8 (aromatic carbon), 140.1 (aromatic carbon), $-0.82\left[-\mathrm{Si}\left(\mathrm{CH}_{3}\right)_{3}\right] . \quad$ FT-IR $\left(\mathrm{NaCl}, \mathrm{cm}^{-1}\right)$ : $878\left[-\mathrm{Si}\left(\mathrm{CH}_{3}\right)_{3}\right]$.

\subsubsection{2,8-Bis(dimethylsilyl)dibenzothiophene (3b)}

2,8-Bis(dimethylsilyl)dibenzothiophene (3b) was synthesized by the similar synthetic method of $\mathbf{3 a}$ using chlorodimethylsilane instead of chlorotrimethylsilane and obtained as colorless liquid with the yield of $83 \%(0.73 \mathrm{~g}$, $2.43 \mathrm{mmol})$.

${ }^{1} \mathrm{H}-\mathrm{NMR}\left(\mathrm{CDCl}_{3}, 400 \mathrm{MHz}\right): \quad \delta \quad 0.46[\mathrm{~d}, J=3.7 \mathrm{~Hz}, 12 \mathrm{H}$, $\left.-\mathrm{Si}\left(\mathrm{CH}_{3}\right)_{2}\right], 4.57-4.61\left[\mathrm{~m}, 2 \mathrm{H},-\mathrm{Si}\left(\mathrm{CH}_{3}\right)_{2}-\mathrm{H}\right], 7.60-7.62(\mathrm{~m}$, $2 \mathrm{H}$, aromatic protons), 7.85-7.87 ( $\mathrm{m}, 2 \mathrm{H}$, aromatic protons), 8.37 (s, $2 \mathrm{H}$, aromatic protons). ${ }^{13} \mathrm{C}-\mathrm{NMR}\left(\mathrm{CDCl}_{3}, 100\right.$ $\mathrm{MHz}$ ): $\delta 122.3$ (aromatic carbon), 127.1 (aromatic carbon), 131.9 (aromatic carbon), 132.9 (aromatic carbon), 134.8 (aromatic carbon), 140.5 (aromatic carbon), -3.41 [-Si $\left.\left(\mathrm{CH}_{3}\right)_{2}-\right]$. FT-IR $\left(\mathrm{NaCl}, \mathrm{cm}^{-1}\right): 1248$ [-Si- $\left.\left(\mathrm{CH}_{3}\right)_{2}\right]$.
2.3.3 Synthesis of 2,8-bis(dimethylhydroxysilyl)dibenzothiophene (M1)

2,8-Bis(dimethylsilyl)dibenzothiophene $(\mathbf{3 b}, 0.500 \mathrm{~g}$, $1.66 \mathrm{mmol})$ dissolved in THF $(10 \mathrm{~mL})$ was added dropwise to a mixture of THF $(10 \mathrm{~mL}), \mathrm{H}_{2} \mathrm{O}(90.0 \mathrm{mg}, 5.00 \mathrm{mmol})$ and $5 \% \mathrm{Pd}-\mathrm{C}(6.00 \mathrm{mg}, 0.0056 \mathrm{mmol})$ at ambient temperature. The reaction mixture was stirred for $26 \mathrm{~h}$ at ambient temperature and filtered. The filtrate was concentrated under reduced pressure. The residue dissolved in chloroform was reprecipitated from hexane to afford 2,8-bis(dimethylhydroxysilyl)dibenzothiophene as colorless crystals with the yield of $48 \%(0.26 \mathrm{~g}, 0.78 \mathrm{mmol})$. M.p.: $164{ }^{\circ} \mathrm{C} . \quad{ }^{1} \mathrm{H}-\mathrm{NMR}$ (DMSO- $d_{6}, 400 \mathrm{MHz}$ ): $\delta$ $0.35-0.37\left[\mathrm{~m}, 12 \mathrm{H},-\mathrm{Si}\left(\mathrm{CH}_{3}\right)_{2}\right], 6.07$ [s, $\left.2 \mathrm{H},-\mathrm{Si}\left(\mathrm{CH}_{3}\right)_{2}-\mathrm{OH}\right]$, 7.66-7.68 (m, 2H, aromatic protons), 8.01-8.03 (m, $2 \mathrm{H}$, aromatic protons), 8.55 (s, $2 \mathrm{H}$, aromatic protons). ${ }^{13} \mathrm{C}-\mathrm{NMR}$ (DMSO- $d 6,100 \mathrm{MHz}$ ): $\delta \quad 122.4$ (aromatic carbon), 126.4 (aromatic carbon), 131.3 (aromatic carbon), 134.3 (aromatic carbon), 136.5 (aromatic carbon), 139.4 (aromatic carbon), 0.94 [-Si $\left.\left(\mathrm{CH}_{3}\right)_{2}-\right]$. FT-IR $\left(\mathrm{KBr}, \mathrm{cm}^{-1}\right)$ : $3274(-\mathrm{OH})$.

\subsubsection{Polycondensation of $\mathbf{M} \mathbf{1}$}

To 2,8-bis(dimethylhydroxysilyl)dibenzothiophene (M1, $0.200 \mathrm{~g}, 0.60 \mathrm{mmol})$ dissolved in benzene $(5 \mathrm{~mL})$, was added a few drops 1,1,3,3-tetramethylguanidinium 2ethylhexanoate. After the reaction mixture was refluxed for $12 \mathrm{~h}$, it was concentrated under reduced pressure. The resulting residue dissolved in chloroform was reprecipitated from methanol to afford dibenzothiophenebased poly(tetramethylsilarylenesiloxane) (P1) as colorless solids with the yield of $32 \%(0.060 \mathrm{~g}, 0.20 \mathrm{mmol})$.

${ }^{1} \mathrm{NMR}\left(\mathrm{CDCl}_{3}, 400 \mathrm{MHz}\right): \delta 0.36\left[\mathrm{~s}, 12 \mathrm{H},-\mathrm{Si}\left(\mathrm{CH}_{3}\right)_{2}\right]$, 7.46-7.53 (m, 2H, aromatic protons), 7.67-7.72 (m, $2 \mathrm{H}$, aromatic protons), $8.24\left(\mathrm{~s}, 2 \mathrm{H}\right.$, aromatic protons). ${ }^{13} \mathrm{C}$ NMR $\left(\mathrm{CDCl}_{3}, 100 \mathrm{MHz}\right): \delta 122.2$ (aromatic carbon), 126.0 (aromatic carbon), 131.0 (aromatic carbon), 134.7 (aromatic carbon), 135.1 (aromatic carbon), 140.6 (aromatic carbon), $1.12\left[-\mathrm{Si}\left(\mathrm{CH}_{3}\right)_{2}-\right]$. FT-IR $\left(\mathrm{KBr}, \mathrm{cm}^{-1}\right)$ : 1053 [Si-O-Si].

\subsubsection{Dibenzothiophene-5,5'-dioxide (10) ${ }^{[16]}$}

Under a dry argon atmosphere, dibenzothiophene (1, $0.800 \mathrm{~g}, 4.34 \mathrm{mmol})$, acetic acid $(13 \mathrm{~mL})$, and $31 \%$ hydrogen peroxide $(2.0 \mathrm{~mL}, 21.7 \mathrm{mmol})$ were mixed. After the resulting reaction mixture was refluxed for $4 \mathrm{~h}$, it was poured into water and filtered. The resulting precipitate was recrystallized from chloroform to afford dibenzothiophene-5,5'-dioxide as colorless crystals with the yield of $57 \%(0.537 \mathrm{~g}, 2.5 \mathrm{mmol})$.

M.p.: $230{ }^{\circ} \mathrm{C} .{ }^{1} \mathrm{H}-\mathrm{NMR}\left(\mathrm{CDCl}_{3}, 400 \mathrm{MHz}\right): \delta 7.51-7.55$ (m, $2 \mathrm{H}$, aromatic protons), 7.63-7.67 (m, $2 \mathrm{H}$, aromatic protons), 7.79-7.84 (m, $4 \mathrm{H}$, aromatic protons). ${ }^{13} \mathrm{C}-\mathrm{NMR}$ $\left(\mathrm{CDCl}_{3}, 100 \mathrm{MHz}\right): \delta 121.6$ (aromatic carbon), 122.2 (aromatic carbon), 130.4 (aromatic carbon), 131.6 (aromatic carbon), 133.9 (aromatic carbon), 137.7 (aromatic carbon). FT-IR $\left(\mathrm{KBr}, \mathrm{cm}^{-1}\right): 1288(\mathrm{~S}=\mathrm{O})$.

2.3.6 2,8-Bis(trimethylsilyl)dibenzothiophene-5,5' -dioxide (3aO)

2,8-Bis(trimethylsilyl)dibenzothiophene-5,5'-dioxide (3aO) was synthesized by the similar synthetic method of 10 using $3 \mathbf{a}$ as the substrate. Recrystallization from the mixed solvent of ethyl acetate and hexane afforded $\mathbf{3 a O}$ as 
colorless crystals with the yield of $53 \%(0.463 \mathrm{~g}, 1.3 \mathrm{mmol})$. M.p.: $230{ }^{\circ} \mathrm{C} .{ }^{1} \mathrm{H}-\mathrm{NMR}\left(\mathrm{CDCl}_{3}, 400 \mathrm{MHz}\right): \delta 0.37[\mathrm{~s}$, $\left.18 \mathrm{H},-\mathrm{Si}\left(\mathrm{CH}_{3}\right)\right], 7.67(\mathrm{~m}, 2 \mathrm{H}$, aromatic protons), $7.78(\mathrm{~m}$, $2 \mathrm{H}$, aromatic protons), 7.92 (s, $2 \mathrm{H}$, aromatic protons). ${ }^{13} \mathrm{C}$-NMR $\left(\mathrm{CDCl}_{3}, 100 \mathrm{MHz}\right): \delta-1.11\left[-\mathrm{Si}\left(\mathrm{CH}_{3}\right)\right], 121.2$ (aromatic carbon), 125.9 (aromatic carbon), 130.9 (aromatic carbon), 135.4 (aromatic carbon), 138.2 (aromatic carbon), 148.7 (aromatic carbon). FT-IR (KBr, $\left.\mathrm{cm}^{-1}\right): 1303(\mathrm{~S}=\mathrm{O})$.

\subsubsection{Oxidation of $\mathbf{P} \mathbf{1}$}

P1 $(0.325 \mathrm{~g}, 1.0 \mathrm{mmol}), m$-CPBA $(0.534 \mathrm{~g}, 3.1 \mathrm{mmol})$, and dichloromethane $(40 \mathrm{~mL})$ were mixed. The resulting reaction mixture was stirred for $18 \mathrm{~h}$ at ambient temperature shielded from light. Then, the reaction solution was poured into sodium thiosulfate aqueous solution and the crude product was extracted with chloroform and washed with sodium hydrogen carbonate aqueous solution. The organic layer was concentrated under reduced pressure. The crude product dissolved in chloroform was reprecipitated from methanol to afford dibenzothiophene5,5'-oxide-based poly(tetramethylsilarylenesiloxane) (P10) as colorless solids with the yield of $78 \%(0.091 \mathrm{~g}$, $0.26 \mathrm{mmol})$.

${ }^{1} \mathrm{H}-\mathrm{NMR}\left(\mathrm{CDCl}_{3}, 400 \mathrm{MHz}\right): \delta \quad 0.36-0.44[\mathrm{~m}, 18 \mathrm{H}$, $-\mathrm{Si}\left(\mathrm{CH}_{3}\right)$ ], 7.67-7.68 (m, 2H, aromatic protons), 7.76-7.78 (m, 2H, aromatic protons), 7.92 (s, 2H,aromatic protons). ${ }^{13} \mathrm{C}-\mathrm{NMR}\left(\mathrm{CDCl}_{3}, 100 \mathrm{MHz}\right): \delta 121.5$ (aromatic carbon), 125.5 (aromatic carbon), 130.9 (aromatic carbon), 135.0 (aromatic carbon), 138.7 (aromatic carbon), 147.1 (aromatic carbon), 0.988 [-Si $\left.\left(\mathrm{CH}_{3}\right)\right]$. FT-IR $\left(\mathrm{KBr}, \mathrm{cm}^{-1}\right)$ : $1171(\mathrm{~S}=\mathrm{O})$.

\section{RESULTS AND DISCUSSION}

3.1 Synthesis of monomer and polymer

Scheme 1 shows the synthetic pathways for dibenzothiophene derivatives (3a, P1, 10, 3aO, and P10). Dibenzothiophene (1) was brominated using bromine to afford 2,8-dibromodibenzothiophene (2) ${ }^{[4]} \quad 2,8$ Bis(trimethylsilyl)dibenzothiophene (3a) and 2,8bis(dimethylsilyl)dibenzothiophene (3b) were synthesized via lithiation reaction of 2 using $n$-BuLi and successive reaction with chlorotrimethylsilane and chlorodimethylsilane, respectively. 2,8-Bis(dimethylhydroxysilyl)dibenzothiophene (M1) was obtained by the hydrolysis of $\mathbf{3 b}$ catalyzed by $5 \%$ Pd-C. M1 underwent polycondensation catalyzed by 1,1,3,3-tetramethylguanidinium 2ethylhexanoate to afford the corresponding dibenzothiophene-based poly(tetramethylsilarylenesiloxane) (P1). Dibenzothiophene-5,5'-dioxide (10) and 2,8-bis(trimethylsilyl)dibenzothiophene-5,5'-dioxide

(3aO) were synthesized by oxidation reaction of $\mathbf{1}$ and $\mathbf{3 a}$, respectively, using $31 \%$ hydrogen peroxide as the oxidant. Dibenzothiophene-5,5'-dioxide-based poly(tetramethylsilarylenesiloxane) (P10) was synthesized by oxidation reaction of P1 using $m$-CPBA as the oxidant. The results of the polycondensation of $\mathbf{M} \mathbf{1}$ and the oxidation of $\mathbf{P} \mathbf{1}$ are summarized in Table I .

Each structure of the obtained compounds was confirmed by the NMR as well as FT-IR spectroscopy. The formation of P1 and P10 was also confirmed by SEC measurement and NMR as well as FT-IR spectroscopy. All NMR spectra of the obtained compounds were consistent with their structures. In addition, the SEC profile of P1 was bimodal, indicating that a small amount of relatively low-molecular weight species such as a cyclic dimer or trimer were involved in the resulting polymer; however, that of $\mathbf{P 1 0}$ was unimodal to confirm that the removal of the low-molecular weight species such as a cyclic dimer or trimer was achieved by reprecipitation procedures. The obtained $\mathbf{P} \mathbf{1}$ and $\mathbf{P} \mathbf{1 0}$ exhibited the good solubility in common organic solvents such as THF, chloroform, dichloromethane, toluene, and so on.

\subsection{Thermal characterization of polymer}

Table I summarizes the thermal properties of each polymer together with the results of polycondensation. The glass transition temperatures $\left(T_{\mathrm{g}}\right)$ of $\mathbf{P} \mathbf{1}$ and $\mathbf{P} \mathbf{1 0}$ were $73{ }^{\circ} \mathrm{C}$ and $150{ }^{\circ} \mathrm{C}$, respectively. The higher $T_{\mathrm{g}}$ of $\mathbf{P} 10$ than that of $\mathbf{P 1}$ would be due to the polarity of dibenzothiophene-5,5'-dioxide moiety higher than that of dibenzothiophene one that increased the inter- and/or intramolecular interactions and that inhibited the mobility of the main chain. No clear endothermal peaks based on melting behavior were observed in the range of $-50{ }^{\circ} \mathrm{C}$ to $400{ }^{\circ} \mathrm{C}$, plausibly indicating that $\mathbf{P 1}$ and $\mathbf{P 1 0}$ were amorphous polymers. The temperatures at $5 \%$ weight loss $\left(T_{\mathrm{d} 5}\right)$ of $\mathbf{P} \mathbf{1}$ and P10 were $496{ }^{\circ} \mathrm{C}$ and $440{ }^{\circ} \mathrm{C}$, respectively. This finding would suggest that the polarity of dibenzothiophene-5,5'-dioxide moiety higher than that of dibenzothiophene one promotes the inter- and/or intramolecular interactions to decrease the thermal stability.

Table I . Characterization of P1 and P10.

\begin{tabular}{cccccc}
\hline Polymer & Yield(\%) & $M_{\mathrm{n}}^{\mathrm{a}}{ }^{\mathrm{a}}$ & $M_{\mathrm{w}} / M_{\mathrm{n}}^{\mathrm{a})}$ & $T_{\mathrm{g}}\left({ }^{\circ} \mathrm{C}\right)^{\mathrm{b})}$ & $\left.T_{\mathrm{d} 5}\left({ }^{\circ} \mathrm{C}\right)^{\mathrm{c}}\right)$ \\
\hline $\mathbf{P 1}$ & 32 & 26000 & 1.44 & 73 & 496 \\
$\mathbf{P} 10$ & 78 & 7000 & 1.05 & & \\
\hline & 17000 & 1.77 & 150 & 440 \\
\hline & Estimated from SEC eluted with THF based on polystyrene standards. \\
Glass transition temperature determined by DSC at a heating rate of \\
$10^{\circ} \mathrm{C} /$ min under a nitrogen atmosphere. \\
Temperature at $5 \%$ weight loss determined by TG at a heating of rate of \\
$10^{\circ} \mathrm{C} /$ min under a nitrogen atmosphere.
\end{tabular}

Figs. 1 and 2 show the absorption and fluorescence spectra of each derivative, respectively. Table II summarizes the optical properties of the obtained dibenzothiophene derivatives. The slight red-shifts owing to the introduction of alkylsilyl groups onto dibenzothiophene and dibenzothiophene-5,5'-dioxide skeletons were observed in the absorption spectra as shown in Fig. 1. On the other hand, the introduction of alkylsilyl groups onto dibenzothiophene skeleton induced the very slight redshifts in the fluorescence spectra; however, the introduction of alkylsilyl groups onto dibenzothiophene-5,5'-dioxide skeleton did the relatively remarkable red-shifts in the fluorescence spectra as shown in Fig. 2. In the previous studies, it was indicated that the introduction of alkylsilyl groups onto aromatic moieties caused the red-shifts in the absorption and fluorescence wavelengths mainly owing to the effects of $\sigma^{*}-\pi^{*}$ conjugation. ${ }^{[7]}$ Thus, the present results would indicate that no remarkable $\sigma^{*}-\pi^{*}$ conjugation is induced between dibenzothiophene moiety and substituted alkylsilyl groups. Fig. 3 shows the molecular orbitals of $\mathbf{1}, \mathbf{3 a}, \mathbf{1 0}$, and $\mathbf{3 a O}$ calculated using the DFT method at the B3LYP/6-31G(d) level. There were no remarkable changes in the orbital shapes of the HOMO and LUMO by the introduction of trimethylsilyl groups, suggesting that the $\sigma^{*}-\pi^{*}$ conjugation is not induced by the $\sigma^{*}$ orbital of silicon and the $\pi^{*}$ orbital of 
carbon at 1 and 9 positions of dibenzothiophene.

Table II . Optical properties of dibenzothiophene derivatives.

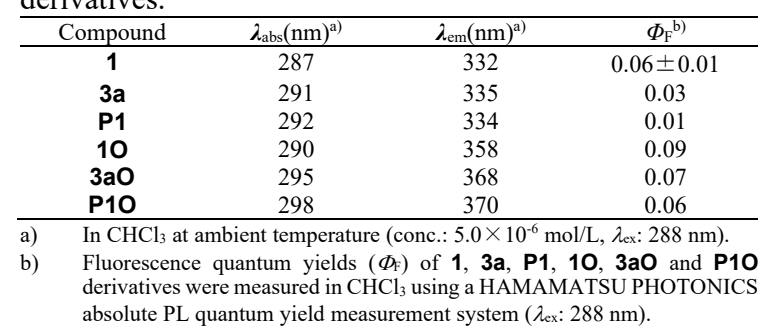

These calculation results are consistent with the spectroscopic results as mentioned above.

As seen in Table II, the improvement in fluorescence quantum yield $\left(\Phi_{\mathrm{F}}\right)$ was not observed by introducing alkylsilyl groups onto dibenzothiophene and dibenzothiophene-5,5'-dioxide skeletons. It has been reported $^{[8]}$ that the introduction of alkylsilyl groups onto aromatic moieties make the intersystem crossing rate constants negligible owing to the energy stabilization of the first single excited state $\left(S_{1}\right)$ to result in the change of the relative energy position against the second triplet state $\left(\mathrm{T}_{2}\right)$. As a result, $\Phi_{\mathrm{F}}$ is increased; however, the introduction of alkylsilyl groups onto dibenzothiophene and dibenzothiophene-5,5'-dioxide skeletons plausibly induced little energy stabilization of $S_{1}$ to result in no remarkable improvement of $\Phi_{\mathrm{F}}$.

In conclusion, we achieved the synthesis of new dibenzothiophene-based poly(tetramethylsilarylenesiloxane) derivative (P1) as well as new oxidized dibenzothiophene-based poly(tetramethylsilarylenesiloxane) derivative (P10) through the oxidation reaction of P1. It was revealed from the absorption and fluorescence spectroscopy as well as the calculation using the DFT method that the present dibenzothiophene derivatives having alkylsilyl moieties exhibit the specific fluorescent property owing to no remarkable appearance of $\sigma^{*}-\pi^{*}$ conjugation between dibenzothiophene and alkylsilyl groups.

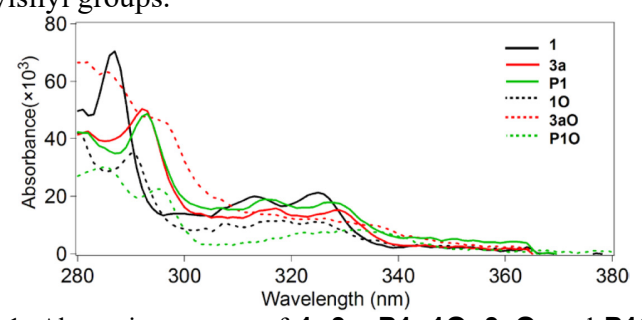

Fig. 1. Absorption spectra of $\mathbf{1}, \mathbf{3 a}, \mathbf{P 1}, \mathbf{1 0}, \mathbf{3 a O}$, and $\mathbf{P} \mathbf{1 0}$ in $\mathrm{CHCl}_{3}$ at ambient temperature (conc.: $5.0 \times 10^{-6} \mathrm{~mol} / \mathrm{L}$ ).

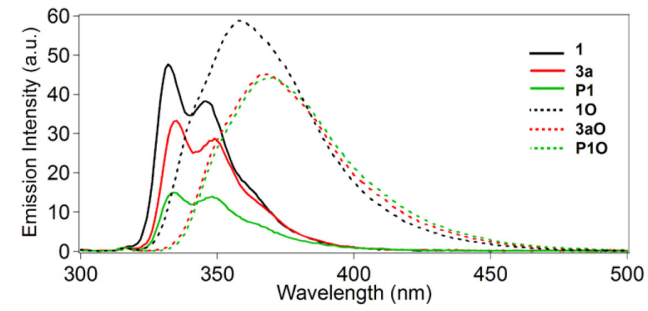

Fig. 2. Fluorescence spectra of $\mathbf{1}, \mathbf{3 a}, \mathbf{P} \mathbf{1}, \mathbf{1 0}, \mathbf{3 a O}$, and $\mathbf{P} \mathbf{1 0}$ in $\mathrm{CHCl}_{3}$ at ambient temperature (conc.: $5.0 \times 10^{-6} \mathrm{~mol} / \mathrm{L}, \lambda_{\text {ex }}: 288$ $\mathrm{nm})$.

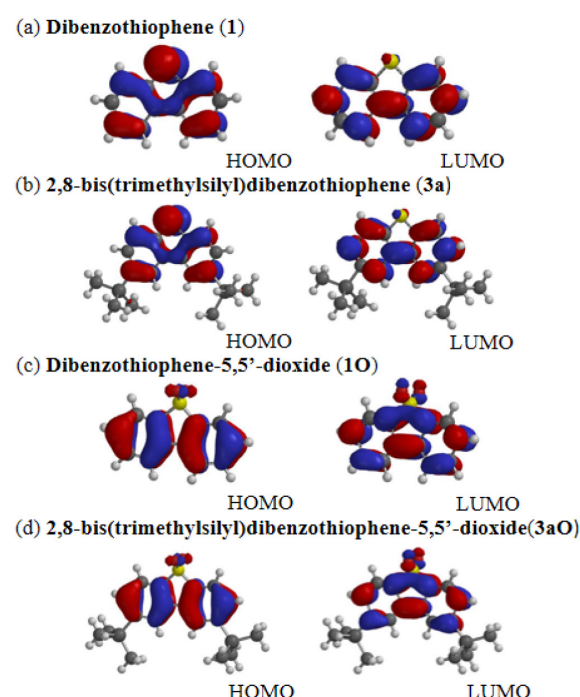

Fig.3. Molecular orbitals of $\mathbf{1}$ (a), $\mathbf{3 a}$ (b), $\mathbf{1 0}$ (c) and $\mathbf{3 a O}$ (d) calculated using the DFT method at the B3LYP/6-31G(d) level.

\section{ACKNOWLEDGEMENT}

The authors would like to appreciate Ms. Misa Fukushima, Graduate School of Engineering, Nihon University, for performing the fluorescence quantum yield measurement.

\section{REFERENCES}

[1] B. Chawla, F. D. Sanzo, J. Chromatogr., 589, 271-279 (1992).

[2] O. Shimomura, T. Sato, I. Tomita, M. Suzuki, T. Endo, J. Polym. Sci., Part A: Polym. Chem., 35, 2813-2819 (1997).

[3] N. S. Allen, T. Corrales, M. Edge, F. Catalina, M. Blanco-Pina, A. Green, Polymer, 39, 903-909 (1998).

[4] N. Nemoto, H. Kameshima, Y. Okano, T. Endo, J. Polym. Sci. Part A: Polym. Chem., 41, 1521-1526 (2003).

[5] P. Pahlavanlu, P. R. Christensen, J. A. Terrien, M. O. Wolf, J. Phys. Chem. C, 120, 70-77 (2016).

[6] H. Shizuka, Y. Sato, Y. Ueki, M. Ishikawa, M. Kumada, J. Chem. Soc., Faraday Trans. 1, 80, 341357 (1984).

[7] S. Kyushin, T. Matsuura, H. Matsumoto, Organometallics, 25, 2761-2765 (2006).

[8] T. Karatsu, J. Photochem. Photobiol. C, Photochem. Rev., 9, 111-137 (2008).

[9] H. Hanamura, R. Haneishi, N. Nemoto, Tetrahedron Lett., 52, 4039-4041 (2011).

[10] K. Imai, T. Sasaki, J. Abe, A. Kimoto, Y. Tamai, N. Nemoto, Polym. J., 41, 584-585 (2009).

[11] K. Imai, Y. Kihara, A. Kimoto, J. Abe, Y. Tamai, N. Nemoto, Polym. J., 43, 58-65 (2011).

[12] K. Imai, T. Sasaki, J. Abe, N. Nemoto, Polym. Bull., 68, 1589-1601 (2012).

[13] H. Hanamura, N. Nemoto, Polymer, 52, 5282-5289 (2011).

[14] H. Hanamura, N. Nemoto, Polymer, 55, 6672-6679 (2014).

[15] I. Nishizawa, H. Ajito, Y. Gonmori, R. Katoh, T. Ichikawa, N. Nemoto, Polymer, 167, 93-101 (2019).

[16] F. Yang, K. Sun, Z. J. Cao, Z. H. Li, M. S. Wong, Synth. Met., 158, 391-395 (2008).

(Received October 2, 2019; Accepted January 20, 2020;

Published Online April 1, 2020) 